\title{
Epidemiology of substance abuse among migrants compared to native born population in primary care
}

Running head: Substance abuse among migrants compared to native born population

\begin{abstract}
:
Background and Objectives: Research in the United States tends to indicate that immigrants from most sociogeographic regions have considerably lower substance use disorder (SUD) rates than native born individuals. We aimed to analyze the differences between immigrants and native born population regarding substance abuse and dependence. This objective was approached using data from the ARACAT cross-sectional multicenter study in primary care settings of two different Spanish regions: Aragon and Catalonia.

Methods: 3006 patients (1503 immigrants randomly selected and 1503 native born paired by age and gender) were interviewed using the Mini-International Neuropsychiatric Interview.

Results: Reported substance abuse and dependence was more prevalent in native born population than immigrants (Alcohol abuse $5.1 \%$ vs. $2.6 \%$ p<.0001, Alcohol dependence $3.3 \%$ vs. $2.6 \%$ n.s., other abuse $3.4 \%$ vs. $.4 \%$ p <.0001, other dependence $.5 \%$ vs. $4.0 \%$ p <.0001). Large differences were detected among ethnic origins. Sociodemographic characteristics such as female gender, older age, higher level of education or stable housing (among others), were found to be protective against different SUDs.
\end{abstract}

Conclusions and Scientific Significance: Immigrants have lower levels of alcohol and substance abuse, however, those that that do consume show higher levels of both comorbid mental disorders and problematic alcohol/substance use. It would appear to be the case that issues specific to immigrant cultures, such as extreme stigmatization of substance and alcohol use, may serve to promote social marginalization and inhibit treatment access.

Keywords: Immigration, substance use disorder, drug consumption, alcohol consumption, epidemiology 


\section{INTRODUCTION}

The relationship between immigration, culture, and substance abuse, as with most other psychiatric conditions, is complex. Research in the United States tends to indicate that immigrants from most sociogeographic regions have considerably lower substance and alcohol abuse rates than native born individuals ${ }^{1-3}$. It would appear that immigrants bring with them the prevalence rates from their region of origin, which, in general is lower than that found in Western Europe and North America ${ }^{4,5}$. The bulk of research in the area of immigrant and substance and alcohol use has been carried out in the United States, and it is unclear to what extent the findings are generalizable to other countries. Spain, a country with a relatively recent immigration, on the one hand, and elevated levels of substance abuse on the other, can provide an interesting point of comparison. Primary care, particularly in countries that have very low threshold health care systems, is a first line entry point into the mental health and substance abuse treatment network ${ }^{6}$. This may be particularly the case for immigrants who either are not aware of specialized drug treatment services, or, due to stigma associated with drug and sometimes alcohol use avoid being seen receiving substance abuse treatment. Thus it would also appear that primary care represents not only a potential screening site, but also a "safe" place for attending to substance or alcohol use problems, precisely because there is no stigma associated with primary care visits.

To date, no studies have been identified which examine alcohol and substance use rates in immigrants attending primary care in Spain or elsewhere. A few studies were identified that looked at ethnicity and substance abuse in primary care. One study carried out in New York City found that White Americans had a substance use disorder prevalence of $11.8 \%$, followed by Black Americans (9.1\%), Hispanic Americans (7.5\%), and other ethnic group (5.3\%). Immigration status was not specified ${ }^{6}$. In a study carried out in Rhode Island, it was found that $14.3 \%$ Black women smoked marijuana during the previous month, followed by $10.8 \%$ of Whites, $7.7 \%$ of other ethnic group, and 4.6\% of Hispanics. No data was collected for men. A South African study found that $12.3 \%$ and $12.9 \%$ of Blacks and Coloureds showed hazardous alcohol use respectively, and that $2.5 \%$ and $4.9 \%$ showed hazardous "other drug" use ${ }^{7}$.

Research concerning substance use prevalence in different immigrant groups is sparse, particularly in the Spanish context. One study noted that more than half of the Latin American immigrant sample considered alcohol is easier to access and there are more occasions on which to drink in Spain than in their native countries. Relatedly, 37\% reported drinking more in Spain than back home ${ }^{8}$. Studies 
carried out in the United States indicate that Mexican ${ }^{2,9}$ immigrants have lower alcohol and drug use rates than their U.S. born counterparts. The same goes for Southeast Asians ${ }^{10,11}$ and Arab Americans ${ }^{12}$. There is some indication, however, that those few immigrants that do consume substances or alcohol show greater impairment in the form of elevated levels of dependence, abuse or dual diagnosis. The rates of highly problematic substance and alcohol use and dual diagnosis in drug and alcohol users are higher in the substance using immigrant populations relative to the native born population. This can be seen, for example, in that majority group members in the U.S. had significantly higher rates of past month alcohol use compared to Arab Americans, however, the two groups have the same rates of both binge and heavy alcohol use in the past month as measured by the Michigan Behavioral Risk Factor Survey ${ }^{12}$. Another study found the proportion of excessive drinking and intoxication is higher in foreign-born Latinos, Asians, and Africans, relative to their native born counterparts ${ }^{13}$.

Although all studies reviewed found that substance abuse levels are lower in foreign born populations, there are clear differences in research findings concerning dual diagnosis. A study of Latinos in the United States, as part of the National Latino and Asian American Survey (NLAAS) found that foreign born Latinos had lower levels of dual diagnosis ${ }^{14}$. Surveying data from the Collaborative Psychiatric Epidemiology Studies (CPES) of which the above NLAAS was a part, Mericle, Ta Park, Holck, \& Arria ${ }^{15}$ found that, in general, Whites had higher levels of dual diagnosis than non-Whites, although Asians with a history of drug use disorders had a higher prevalence of dysthymia than Whites and Latinos, and a higher prevalence of panic disorder than Whites. On the other hand, the National Epidemiological Survey and Alcohol and Related Conditions found that dual diagnosis was elevated amongst ethnic minority groups ${ }^{16}$, and a study carried out in Great Britain found higher levels of dual diagnosis in immigrants who than in native British ${ }^{17}$. The objective of this study is to explore differences in alcohol and substance use and abuse in immigrant versus non-immigrant populations on the one hand, and between immigrant groups on the other. Drawing from the existing research literature, it is hypothesized that immigrants will have lower levels of substance use than their native born counterparts, however, those that do use will show more acute/problematic consumption profile and have higher levels of dual diagnosis. 


\section{METHOD}

Study Design

This study was part of the ARACAT project, a multicenter, cross-sectional study, carried out in primary care settings in two Spanish regions (Catalonia and Aragon). The health census (registered access to the public health system) of the immigrant population in both regions was used to calculate the sample size. At every primary health center, the immigrant population that fulfilled inclusion criteria was invited to participate until the required number stratified by ethnic, gender and age groups was met. More details can be consulted elsewhere ${ }^{18}$.

\section{Measures}

In addition to sociodemographic information, alcohol and drug use and comorbidities were recorded using the Spanish version ${ }^{19}$ of the Mini-International Neuropsychiatric Interview, MINI ${ }^{20}$. For this study, the variables of alcohol and drug use, abuse and dependence were used. Somatic presentations were assessed with the somatic symptom section of the Standardized Polyvalent Psychiatric Interview, SPPI ${ }^{21}$. Comorbidity was determined using any DSM-IV diagnosis as measured by the MINI or SPPI excluding drug and alcohol abuse and dependence. All the instruments have been validated in Spanish, English and French, the languages used in the interviews. If patients did not understand any of these languages the interview was not conducted.

The interviews were carried out by master's level psychologists and physicians, who were trained to use the MINI and the other instruments, during the period from January 2007 to December 2008.

All patients provided informed consent before inclusion in the study. This research followed Helsinki Convention norms and its later amendments as well as the World Psychiatric Association Madrid Declaration on Ethical Standards for Psychiatric Practice. The study was approved by the Clinical Research Ethics Committee of Vall d'Hebron and Miguel Servet Universtity Hospitals.

\section{Statistical analyses}

Qualitative sociodemographic and substance use, abuse and dependence variables were dichotomized and differences across native born and immigrant groups were analyzed using odds ratio and chisquare tests. Only income, a quantitative variable, was analyzed using a student-t test. Variables 
found to be bivariately associated with ethnic group or diagnosis of abuse or dependence were included in multivariate forward stepwise logistic regressions aiming to identify variables associated with substance or alcohol use, abuse and dependence. For these analyses region of origin was coded using dummy variables (dichotomously for each origin). Statistical analyses were conducted using SPSS 18.0. A 95\% confidence interval was used for all statistical tests.

\section{RESULTS}

From an initial pool of 3766 screened patients, 3006 met inclusion criteria (80\% response rate) and agreed to participate in the study. Only 9 participants did not provide information about substance use and therefore were excluded from the present study.

Socio-demographic characteristics of the sample are summarized in Table 1 . There were differences in all sociodemographic variables (except for sex and age which were controlled). A more detailed account of sociodemographic characteristics of the sample can be seen elsewhere ${ }^{18}$.

Table 1. Sociodemographic characteristics of the sample (excluding participants without substance information)

\begin{tabular}{|c|c|c|c|c|c|c|c|}
\hline & \multicolumn{2}{|c|}{$\begin{array}{l}\text { Immigrants } \\
(\mathrm{N}=1,499)\end{array}$} & \multicolumn{2}{|c|}{$\begin{array}{l}\text { Native } \\
(\mathrm{N}=1, \mathbf{5 0 0})\end{array}$} & born & \multirow[b]{2}{*}{$\mathrm{t}$} & \multirow[b]{2}{*}{$p$} \\
\hline & M & $\mathrm{SD}$ & M & $\mathrm{SD}$ & & & \\
\hline Age* & 32.5 & 9.3 & 32.5 & 9.4 & -- & -- & -- \\
\hline \multirow[t]{2}{*}{ Income** } & 2.0 & .5 & 2.3 & .6 & & 11.019 & $<.0001$ \\
\hline & $\mathrm{N}$ & $\%$ & $\mathrm{~N}$ & $\%$ & OR & $95 \% \mathrm{CI}$ & $p$ \\
\hline Gender ( $\%$ female $)$ & 920 & 61.3 & 919 & 61.3 & -- & -- & -- \\
\hline Living in rural area $(\%) * * *$ & 34 & 2.3 & 62 & 4.1 & .538 & $.352-.823$ & $<.005$ \\
\hline \multicolumn{8}{|l|}{ Marital status } \\
\hline (\% with couple) & 815 & 55.1 & 669 & 44.9 & 1.508 & $1.305-1.742$ & $<.0001$ \\
\hline \multicolumn{8}{|l|}{ Education } \\
\hline (\% (at least secondary) & 1021 & 68.8 & 1109 & 74.6 & .750 & $.639-.880$ & $<.0001$ \\
\hline \multicolumn{8}{|l|}{ Housing } \\
\hline (\% (home owner/renter) & 913 & 61.4 & 1345 & 91.4 & .150 & $.122-.185$ & $<.0001$ \\
\hline \multicolumn{8}{|l|}{ Employment } \\
\hline (\% active) & 1079 & 72.2 & 1219 & 82.4 & .555 & $.465-.661$ & $<.0001$ \\
\hline
\end{tabular}


Table 2 shows alcohol and psychoactive substance use, abuse and dependence for both groups. Significant differences are observed between immigrants and non-immigrants according to results of the MINI psychiatric interview for alcohol use and abuse but not for dependence. The rate of psychoactive drug use, abuse and dependence were statistically different between groups from different geographic regions of origin.

Table 2. Drug and alcohol use, abuse, and dependence in immigrants and native born population.

\begin{tabular}{|c|c|c|c|c|c|c|c|c|c|c|c|c|c|c|}
\hline & \multicolumn{4}{|c|}{ Immigrants } & \multicolumn{10}{|c|}{ Native Born } \\
\hline & \multicolumn{2}{|l|}{ Rate } & \multicolumn{2}{|c|}{ Dual* $^{*}$} & \multicolumn{2}{|l|}{ Rate } & \multicolumn{2}{|c|}{ Dual* } & \multicolumn{3}{|c|}{ Significance rate } & \multicolumn{3}{|c|}{ Significance dual } \\
\hline & $\mathrm{N}$ & $\%$ & $\mathrm{~N}$ & $\%$ & $\mathrm{~N}$ & $\%$ & $\mathrm{~N}$ & $\%$ & OR & $95 \%$ & $p$ & OR & $95 \% \mathrm{CI}$ & $p$ \\
\hline $\begin{array}{l}3 \text { or more alcoholic } \\
\text { drinks within } 3 \text { hour }\end{array}$ & 200 & 13.3 & 72 & 4.8 & 506 & 33.7 & 113 & 7.5 & .302 & $\begin{array}{l}.252- \\
.363\end{array}$ & $<.0001$ & 1.937 & $\begin{array}{l}1.335- \\
2.769\end{array}$ & $<.0001$ \\
\hline $\begin{array}{l}\text { nerind on } 3 \text { or more } \\
\text { Alcohol dependence } \\
\text { current (past } 12\end{array}$ & 39 & 2.6 & 26 & 1.7 & 50 & 3.3 & 23 & 1.5 & .775 & $\begin{array}{l}.506- \\
1.185\end{array}$ & .238 & 2.449 & $\begin{array}{l}1.011- \\
5.933\end{array}$ & 0.045 \\
\hline $\begin{array}{l}\text { months) } \\
\text { Alcohol } \\
\text { current } \\
\text { months) }\end{array}$ (past 12 & 39 & 2.6 & 23 & 1.5 & 76 & 5.1 & 27 & 1.8 & .500 & $\begin{array}{l}.338- \\
.741\end{array}$ & $<.0001$ & 2.502 & $\begin{array}{l}1.131- \\
5.538\end{array}$ & 0.022 \\
\hline $\begin{array}{l}\text { Take any drug more } \\
\text { than once to get high, }\end{array}$ & 45 & 3.0 & 24 & 1.6 & 235 & 15.7 & 94 & 6.3 & .167 & $\begin{array}{l}.120- \\
.231\end{array}$ & $<.0001$ & 1.666 & $\begin{array}{l}0.877- \\
3.165\end{array}$ & 0.117 \\
\hline $\begin{array}{l}\text { feel better. or change } \\
\text { Nonalcohol } \\
\text { dependence current } \\
\text { (nast } 12 \text { months) }\end{array}$ & 8 & .5 & 6 & 0.04 & 60 & 4.0 & 29 & 1.9 & .129 & $\begin{array}{l}.061- \\
.270\end{array}$ & $<.0001$ & 3.103 & $\begin{array}{l}0.579- \\
16.647\end{array}$ & 0.170 \\
\hline $\begin{array}{l}\text { Nonalcohol abuse, } \\
\text { current (past } 12\end{array}$ & 6 & .4 & 6 & 0.04 & 51 & 3.4 & 23 & 1.5 & .114 & $\begin{array}{l}.049- \\
.267\end{array}$ & $<.0001$ & 1.261 & $\begin{array}{l}1.047- \\
1.518\end{array}$ & $0.024 * *$ \\
\hline
\end{tabular}

*Number and percent of patients with at least one other comorbid non-substance use related Axis I disorder.

**Fisher's exact test (performed due to empty cells).

Table 3 describes the adjusted models of variables relevant to alcohol and psychoactive substance use in the immigrant and Spanish populations. Variables with less than five cases were excluded from these analyses (Eastern European, Sub-Saharan and Asiatic for alcohol dependence; North African, Eastern European, Sub-Saharan and Asiatic for alcohol abuse; Sub-Saharan for Drug use; drug abuse and dependence could only be analyzed using the Spaniard variable). As can be seen in the table, the most important mediators were geographic region of origin, marital status, education, gender, age and housing.

Table 3. Adjusted models of alcohol and psychoactive drug use, dependence and abuse in immigrant and autochthonous populations

\begin{tabular}{llcccc}
\hline & Variable & OR & 95\% CI & p \\
\hline Alcohol use & & & & & \\
\hline & Native born & 3.229 & $2.368-$ & 4.404 & .000 \\
& North African & .538 & $.313-$ & .924 & .025 \\
\multirow{2}{*}{ Nagelkerke R square $=0.203$} & Sub-Saharan & .413 & $.231-.737$ & .003 & .041
\end{tabular}




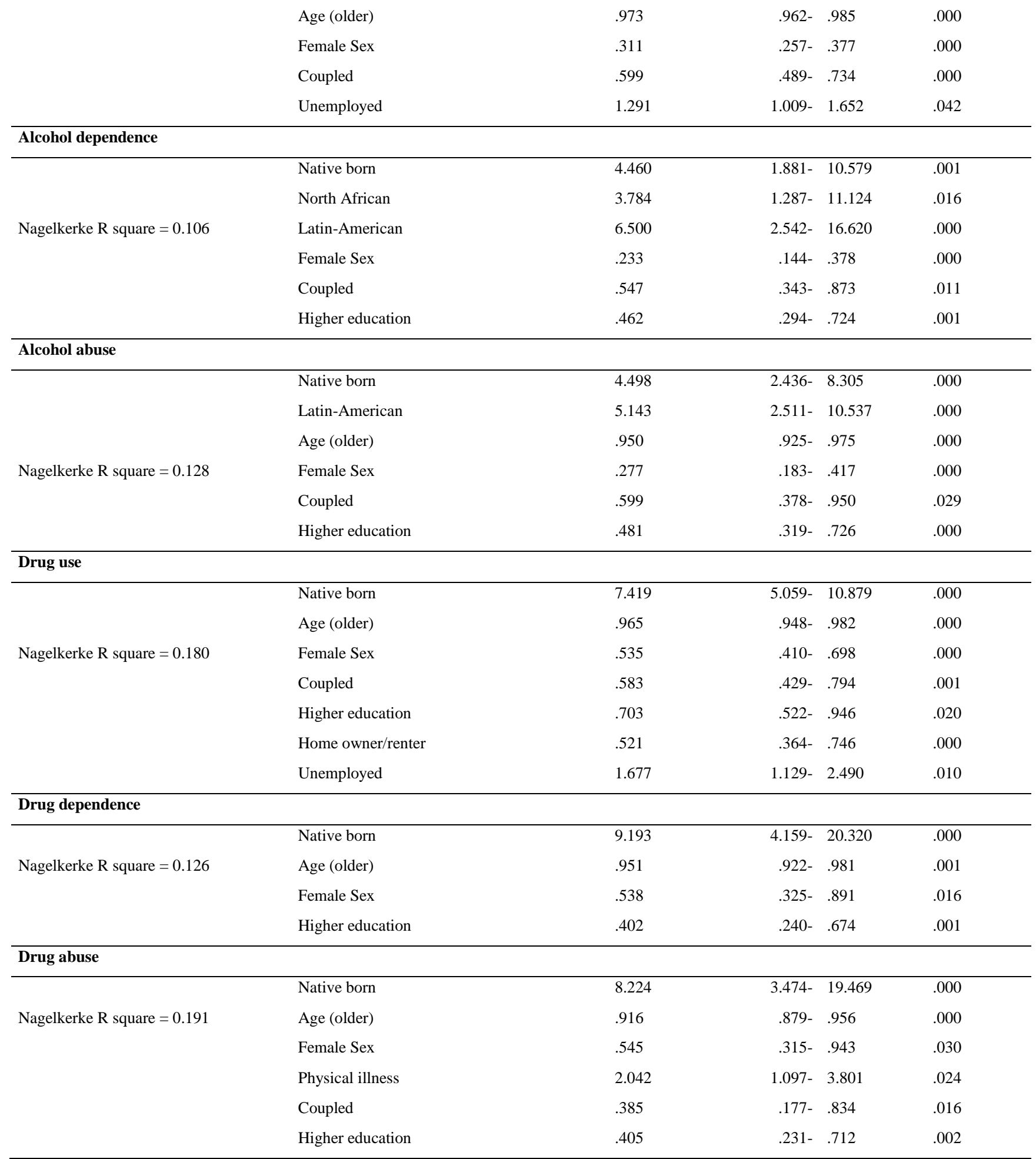

\section{Dual Diagnosis}

As can be seen in table 4, those immigrants who use drugs and alcohol show a higher rate of psychiatric comorbidity than does the native born population. This was only statistically significant for alcohol use, abuse and dependence, and not the case for other drugs, most likely due to the low number of immigrants who reported drug use. 
Table 4. Presence of a psychiatric disorder between drug and alcohol use, abuse and dependence in immigrants and native born population.

\begin{tabular}{lcccccccc}
\hline & \multicolumn{1}{c}{ Immigrants* } & \multicolumn{3}{c}{ Native } \\
& \multicolumn{1}{c}{ Rorn* } & & & \\
& $\mathrm{N}$ & $\%$ & $\mathrm{~N}$ & $\%$ & $\mathrm{OR}$ & $95 \% \mathrm{CI}$ & $p$ \\
\hline 3 or more alcoholic drinks within 3 hour period on 3 & 72 & 36.4 & 113 & 22.8 & 1.937 & $1.335-2.769$ & $<.0001$ \\
Alcohol dependence current (past 12 months) & 26 & 68.4 & 23 & 46.9 & 2.449 & $1.011-5.933$ & 0.045 \\
Alcohol abuse, current (past 12 months) & 23 & 59.0 & 27 & 36.5 & 2.502 & $1.131-5.538$ & 0.022 \\
\hline Take any drug more than once to get high, feel better, & 24 & 53.7 & 94 & 40.7 & 1.666 & $0.877-3.165$ & 0.117 \\
Nonalcohol dependence current (past 12 months) & 6 & 75.0 & 29 & 49.2 & 3.103 & $0.579-$ & 0.170 \\
Nonalcohol abuse, current (past 12 months) & 6 & 100 & 23 & 46.0 & 1.261 & $1.047-1.518$ & $0.024 * *$ \\
\hline
\end{tabular}

*Positive for a psychiatric disorder amongst those reporting alcohol and drug use, abuse or dependence

**Fisher's exact test (performed due to empty cells).

\section{DISCUSSION}

Consistent with the study hypothesis and research carried out elsewhere, immigrants have lower levels of alcohol and drug use and abuse relative to native born Spaniards. Alcohol use is 3 times higher in the native born group, as was to be expected, however, there was no difference in alcohol dependence, and alcohol abuse is twice as high in the native born group relative to the immigrant group. Self-reported drug use is five times higher in the native born group, with the difference being even higher for dependence and abuse.

In general, being male, younger, single, and having fewer years of school education were risk factors for alcohol and drug use. More specifically, for both alcohol abuse and dependence, being from Latin America was a risk factor, and for alcohol use, being unemployed increased the odds. What is perhaps the most notable finding from the study is that those immigrants who do consume alcohol and drugs show elevated levels of impairment, both in terms of drug and alcohol dependence and abuse as well as psychiatric comorbidity. Of the 506 native born Spaniards who were identified as users, $10 \%$ showed dependence and 15\% showed abuse. On the other hand, of the 200 immigrants who were identified as drinkers, $20 \%$ showed both dependence and abuse. It may be the case that stigmatization means that those who use and abuse drugs and alcohol end up marginalized ${ }^{22}$, either due to community rejection or self-isolation related to shame. This marginalization, in turn, could contribute to more risky behavior ${ }^{23}$ and more problematic drug use ${ }^{24}$.

Dual diagnosis was expected to be higher in the immigrant population, however no overall differences were found with comorbid alcohol use and dependence between the two groups. There 
are higher levels of comorbid mental disorder in the immigrant drug and alcohol using population, differences that do not reach significance for drug use and dependence; (due to the low number of immigrants with self-reported drug dependence (6)). Consistent with previous studies carried out in the United States (e.g. Smith et al. ${ }^{16}$ ), it may well be that those immigrants who are exposed to higher levels of stress and/or have fewer resources with which to confront their difficulties are more prone to both substance use as well as other mental health problems.

The stigma may also be related to the study findings themselves. For both alcohol but especially illegal drugs, immigrants reported very little use. It may be the case that they understated their "real" levels of use, particularly of drugs, given the extant stigma associated with drugs in their community. Relatedly, it is possible that immigrants underreport their drug and alcohol use to fears of deportation 25 . Conversely, it may simply be that those who were attending their primary care physician were precisely that population that are under care and as such not those who are at risk for drug use, that is, it may be that this particular population, for its specific characteristics - voluntarily attending a visit with their family doctor and agreeing to participate in the study - may simply have lower rates of use. What does appear to be noteworthy is that immigrants with alcohol and substance use and abuse, although not necessarily high in number, represent a particularly vulnerable population who may well require specialized services given the complexity of their situation.

Adequate response to the treatment needs of migrant patients in both primary care and drug treatment centers requires an understanding of the overall problematic. What this study clearly indicates is that although the overall number of immigrants with drug and alcohol related problems may be low relative to the native born population, those who do consume are more likely to do so problematically or have a co-existing mental disorder. We also see that all immigrant groups are not the same, to the extent that the odds ratio for alcohol abuse is higher in the Latin American immigrant population relative to the native born population, even if overall alcohol use is lower. Being in a stable relationship, with higher education, adequate housing, and employment all combine to lower the risk of drug and alcohol use related problems. Taken together, it may well be the case that for the most part the "immigrant health paradox" functions such that immigrants in general are protected from drug and alcohol use and dependence. Those immigrants, however, who lack the resources to manage the stress related to the migratory experience and those who are more vulnerable, be it for psychological or neurological reasons, to substance abuse are precisely those who will end up with more serious drug and alcohol use problems. 
Limitations: As noted elsewhere ${ }^{18}$, we have no way of ascertaining the validity of the instruments used in this study. We do not know, for example, if the participants, particularly those whose mother tongue is not Spanish, fully understood the questions, nor if the interviewer fully understood the response. Because this study relied on self-report it is unclear the degree to which the results are accurate or indeed are under-reported due to stigma and social desirability. Finally, that this study was carried out in primary care may have conditioned both the immigrant and native born sample; patients may have been reluctant to acknowledge drug and/or alcohol problems out of concern for the possible reaction of their physician, and it may be the case that a certain sub-group of drug and alcohol users do not make use of primary care services.

\section{Acknowledgements}

The authors would like to express their deep appreciation to all of the people who made this study possible, particularly the volunteer interviewers.

The authors would also like to thank the anonymous reviewers for their helpful remarks. The study was supported by a grant from the Carlos III Health Institute to, a grant from the Departament de Salut, Government of Catalonia, Spain, and a doctoral grant from the Research Institute of the Vall d'Hebron University Hospital.

\section{Declaration of Interest}

The authors report no conflicts of interest. The authors alone are responsible for the content and writing of this paper 


\section{REFERENCES}

1. Alegria M, Mulvaney-Day N, Torres M, Polo A, Cao Z, Canino G. Prevalence of psychiatric disorders across Latino subgroups in the United States. American Journal of Public Health. 2007;97(1):68-75.

2. Grant BF, Stinson FS, Hasin DS, Dawson DA, Chou SP, Dufour MC, et al. Prevalence and co-ocurrence of substance use disorders and independent mood and anxiety disorders: results from the National Epidemiologic Survey on Alcohol and Related Conditions. Archives of General Psychiatry. 2004;61:807-16.

3. Johnson TP, VanGeest JB, Ik Cho Y. Migration and substance abuse: Evidence from the U.S. National Health Interview Survey. Substance Use and Misuse. 2002;37(8-10):941-72.

4. United Nations Office on Drugs and Crime. World Drug Report. Vienna: United Nations Office on Drugs and Crime; 2009.

5. Vega WA, Aguilar-Gaxiola S, Andrade L, Bijl R, Borges G, Caraveo-Anduaga JJ, et al. Prevalence and age of onset for drug use in seven international sites: results from the international consortium of psychiatric epidemiology. Drug and Alcohol Dependence. 2002;68(3):285-97.

6. Olfson M, Shea S, Feder A, Fuentes M, Nomura Y, Gameroff M, et al. Prevalence of anxiety, depresion and substance use disorders in an urban general medical practice. Archives of Family Medicine. 2000;9(9):867-83.

7. Ward C. Thinking outside the Berry boxes: New perspectives on identity, acculturation and intercultural relations. International Journal of Intercultural Relations. 2008;32(2):105-14.

8. Tortajada S, Llorens N, Castellano M, Alvarez FJ, Aleixandre-Benavent R, ValderramaZurián JC. Perception and consumption of alcohol among the immigrant population from Latin America in Valencia region (Spain). Subst Use Misuse. 2010;45(14):2567-78.

9. Borges G, Breslau J, Orozco R, Tancredi DJ, Anderson H, Aguilar-Gaxiola S, et al. A crossnational study on Mexico-US migration, substance use and substance use disorders. Drug Alcohol Depend. Elsevier Ireland Ltd; 2011;117(1):16-23.

10. Wong FY, Huang ZJ, Thompson EE, De Leon JM, Shah MS, Park RJ, et al. Substance Use Among a Sample of Foreign- and U.S.-Born Southeast Asians in an Urban Setting. Journal of Ethnicity in Substance Abuse. 2007;6(1):45-66.

11. Nakamura N, Ialomiteanu A, Rehm J, Fischer B. Prevalence and characteristics of substance use among Chinese and south Asians in Canada. J Ethn Subst Abuse. 2011;10(1):39-47.

12. Arfken CL, Kubiak SP, Farrag M. Acculturation and polysubstance abuse in Arab-American treatment clients. Transcult Psychiatry. 2009;46(4):608-22. 
13. Szaflarski M, Cubbins LA, Ying J. Epidemiology of alcohol abuse among US immigrant populations. J Immigr Minor Health. 2011;13(4):647-58.

14. Vega WA, Canino G, Cao Z, Alegria M. Prevalence and correlates of dual diagnoses in U.S. Latinos. Drug and Alcohol Dependence. 2009;100(1/2):32-8.

15. Mericle A a, Ta Park VM, Holck P, Arria AM. Prevalence, patterns, and correlates of cooccurring substance use and mental disorders in the United States: variations by race/ethnicity. Compr Psychiatry. Elsevier Inc.; 2012;53(6):657-65.

16. Smith SM, Stinson FS, Dawson D a, Goldstein R, Huang B, Grant BF. Race/ethnic differences in the prevalence and co-occurrence of substance use disorders and independent mood and anxiety disorders: Results from the National Epidemiologic Survey on Alcohol and Related Conditions. Psychol Med. 2006;36(7):987-98.

17. Harrison L, Sutton M, Grardiner E. Ethnic Differences in Substance Use and Alcohol-UseRelated Mortality among First Generation Migrants to England and Wales. Substance Use and Misuse. 1997;32(7-8):849-76.

18. Qureshi A, Collazos F, Sobradiel N, Eiroa-Orosa FJ, Febrel M, Revollo-Escudero HW, et al. Epidemiology of psychiatric morbidity among migrants compared to native born population in Spain: a controlled study. Gen Hosp Psychiatry. 2013;35(1).

19. Ferrando L, Franco AL, Soto M, Bobes J, Soto O, Franco L, et al. Mini International Neuropsychiatric Interview. Versión en español 5.0.0. Madrid: Instituto IAP; 1998.

20. Lecrubier Y, Sheehan D, Weiller E, Amorim P, Bonora I, Harnett Sheehan K, et al. The Mini International Neuropsychiatric Interview (MINI). A short diagnostic structured interview: reliability and validity according to the CIDI. European Psychiatry. 1997;12(5):224-31.

21. Lobo A, Campos R, Perez-Echeverria MJ, Izuzquiza J, Garcia-Campayo J, Saz P, et al. A new interview for the multiaxial assessment of psychiatric morbidity in medical settings.

Psychological Medicine. 1993/05/01 ed. 1993;23(2):505-10.

22. Leow DM, Goldstein M, Mcglinchy L. Immigration, Acculturation \& Substance Abuse. 2006.

23. EMCDDA. Understanding and responding to drug use: the role of qualitative research. Lisbon; 2000.

24. Valdez A, Cepeda A, Negi NJ, Kaplan C. Fumando la piedra: emerging patterns of crack use among Latino immigrant day laborers in New Orleans. J Immigr Minor Health. 2010;12(5):737-42.

25. Yates J, Collins T, Chin G. A War on Drugs or a War on Immigrants? Expanding the Definition of "Drug Trafficking" in Determining Aggravated Felon Status for Noncitizens. Md L Rev. 2005;64(3):875-909. 